Témoigner Témoigner. Entre histoire et mémoire

Getuigen Revue pluridisciplinaire de la Fondation Auschwitz

$118 \mid 2014$

Au nom des victimes. Dictature et terreur d'État en Argentine, Chili et Uruguay

\title{
Mémoire en stand by
}

Les anciens camps d'extermination en Pologne

Memory standby, the former extermination camps in Poland

Herinnering stand-by, de voormalige vernietigingskampen in Polen

\section{(2) OpenEdition}

Journals

Édition électronique

URL : http://journals.openedition.org/temoigner/1252

DOI : 10.4000/temoigner.1252

ISSN : 2506-6390

Éditeur :

Éditions du Centre d'études et de documentation Mémoire d'Auschwitz, Éditions Kimé

Édition imprimée

Date de publication : 1 octobre 2014

Pagination : $61-71$

ISBN : 978-2-84174-674-3

ISSN : 2031-4183

Référence électronique

" Mémoire en stand by », Témoigner. Entre histoire et mémoire [En ligne], 118| 2014, mis en ligne le 01 octobre 2015, consulté le 23 octobre 2020. URL : http://journals.openedition.org/temoigner/1252 ;

DOI : https://doi.org/10.4000/temoigner.1252 


\section{Portfolio \\ MÉMOIRE EN STAND BY}

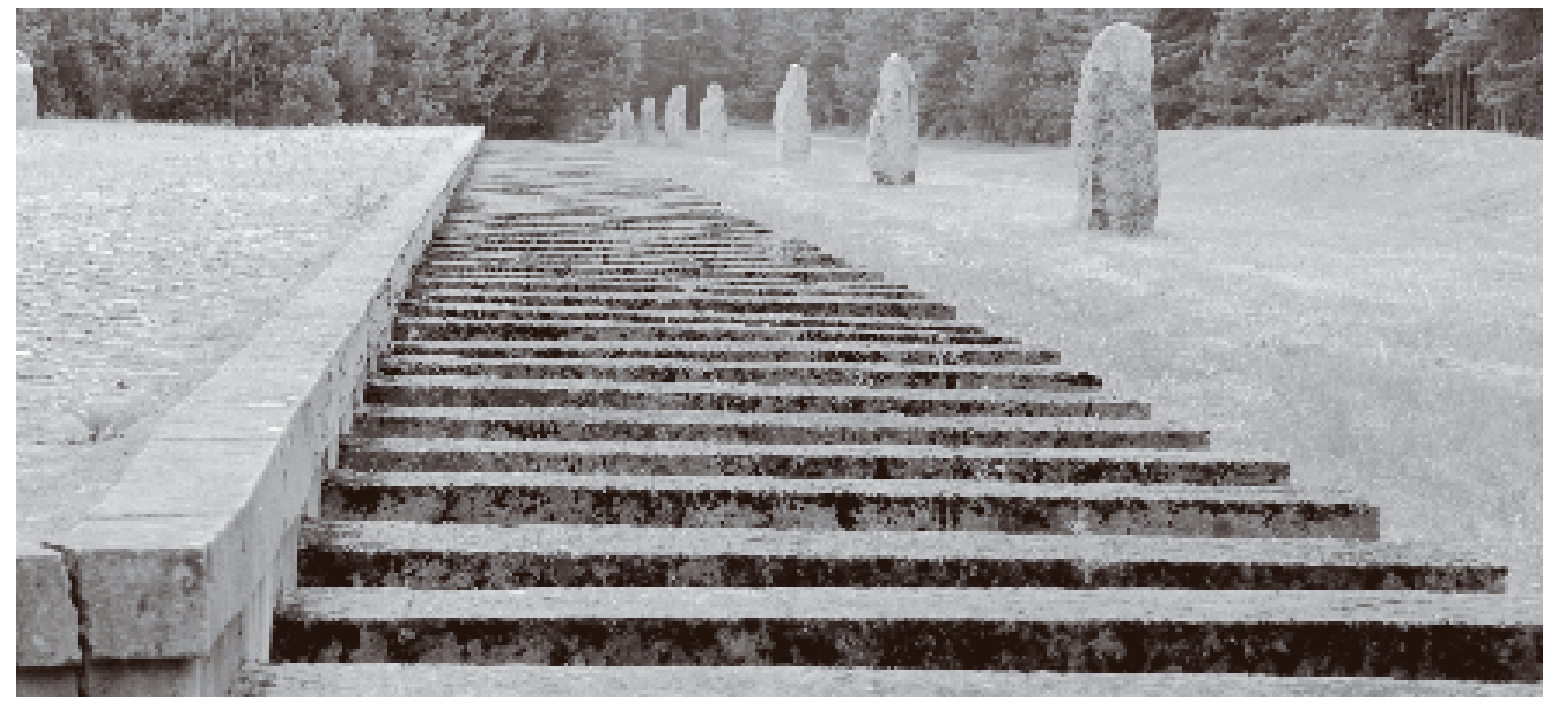

i Auschwitz est entré dans la culture, les cinq autres centres de mise à mort . guère de place et y font peu sens. Bien sûr, aucun portique n’a orné durablement lentrée de ces zones où il n'était pas requis de travailler pour mourir aucun slogan (A.teit mám repère du pir à peine à la surface de la noms flottent à peine à la surface de la conscience actuelle de la Shoah : Chełmno (prenier canpl'externination a avoir été mis en service, indépendamment du Reinhardt) : Majdanek (camp mixte, de même qu'Auschwitz où les SS cazaient les Juifs etles déportés jugés inaptes au travail et oùl'on mourraitde lo vio gazaient les trationno trationnaire). Dé ces cinq canps, seul Majdanék n'a pas été dénantelé par les SS et ses traces effacées. Le premier a avoir informé le grand public de lexistence de ces lieux criminels est Shoah de Claude Lanzmann. Mais a-t-on viaiment retenu ces régulières rediffusions? A-t-on idée du film Betżec de Guillaume Moscovitz (2005)? Même si Auschwitz a été comme l'accomplissement des deux systèmes rénocidaire Même si Auschwitz a été comme laccomplissement des deux systèmes gènocidaire de l'hétérogénéité, de laz dispité et de la ne salt pas ren l'ap cor

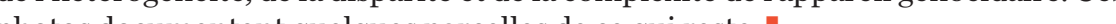




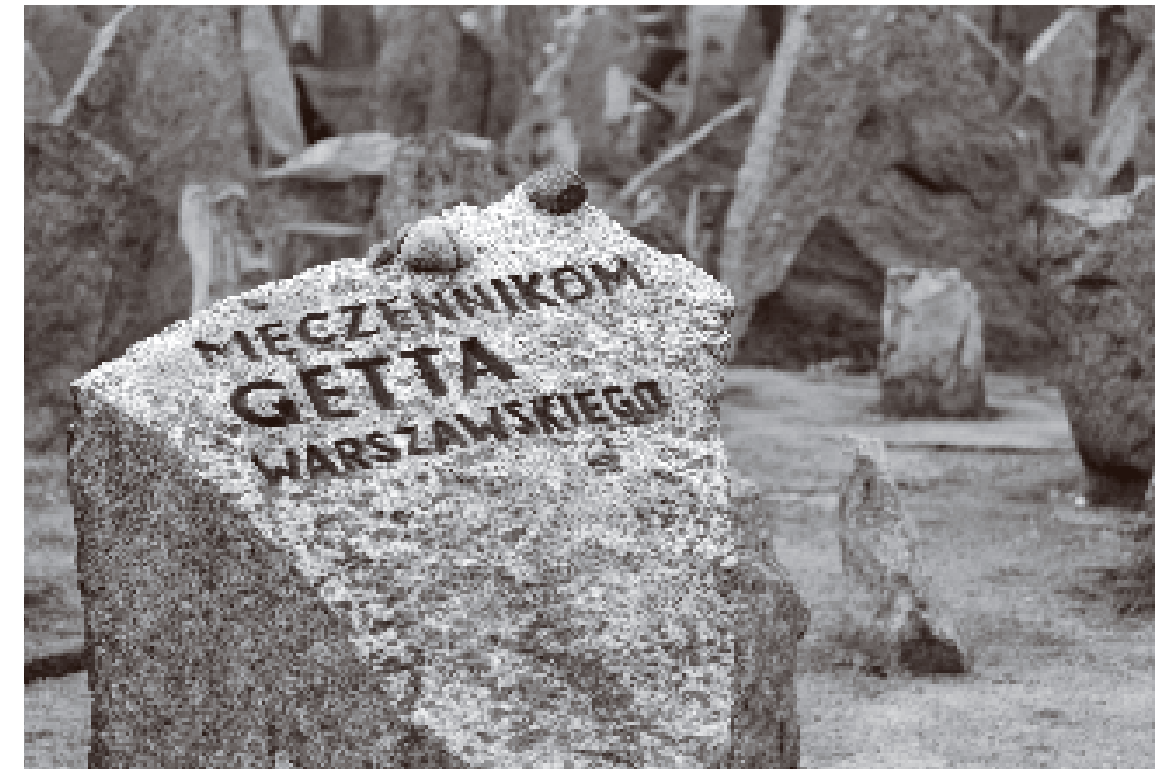

$\checkmark$ Lancien centre d'extermination à Treblink (II) (Monument de 1965) TREBLLNKA I PÉRIOOE D'ACTIVITÉ : 23 JUILLET 1942 - 19 OCTOBRE 1943 I ENVIRON 800000 MORTS

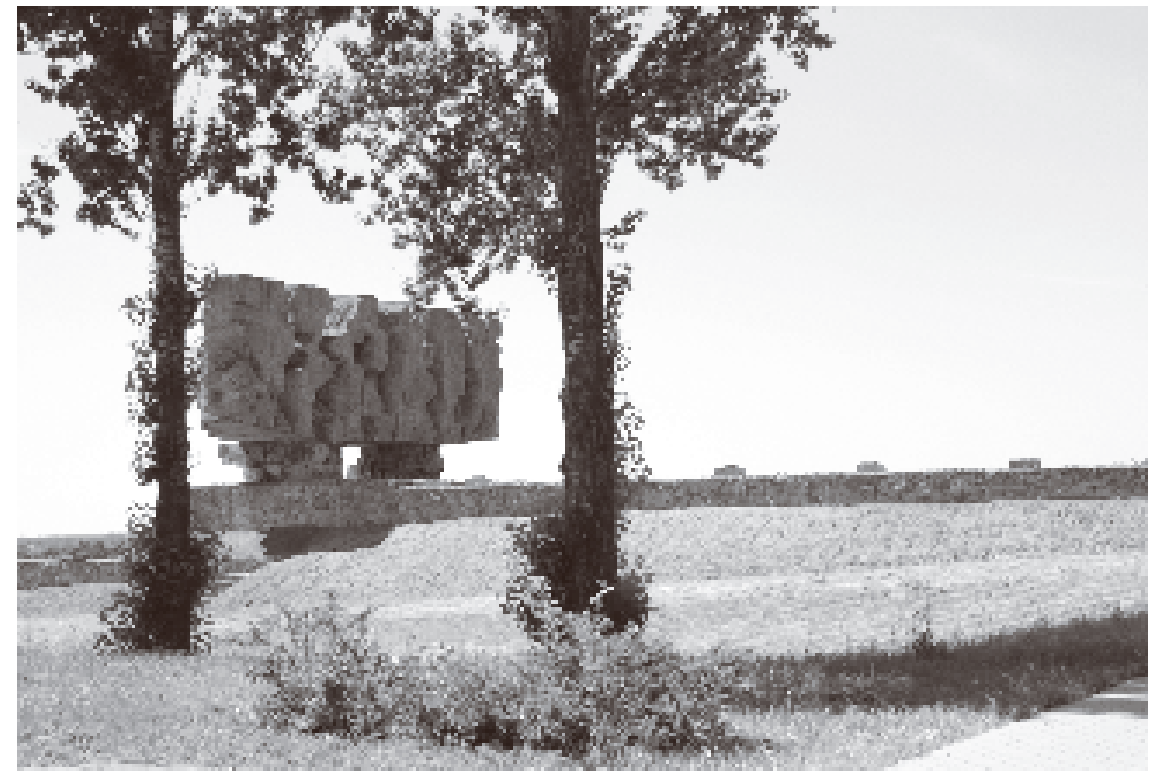

MAJDANEK / PÉRRIODE D'ACTIVITÉ : OCTOBRE 1941 - 23 JULLLET 1944 I ENVIRON 80000 MORTS
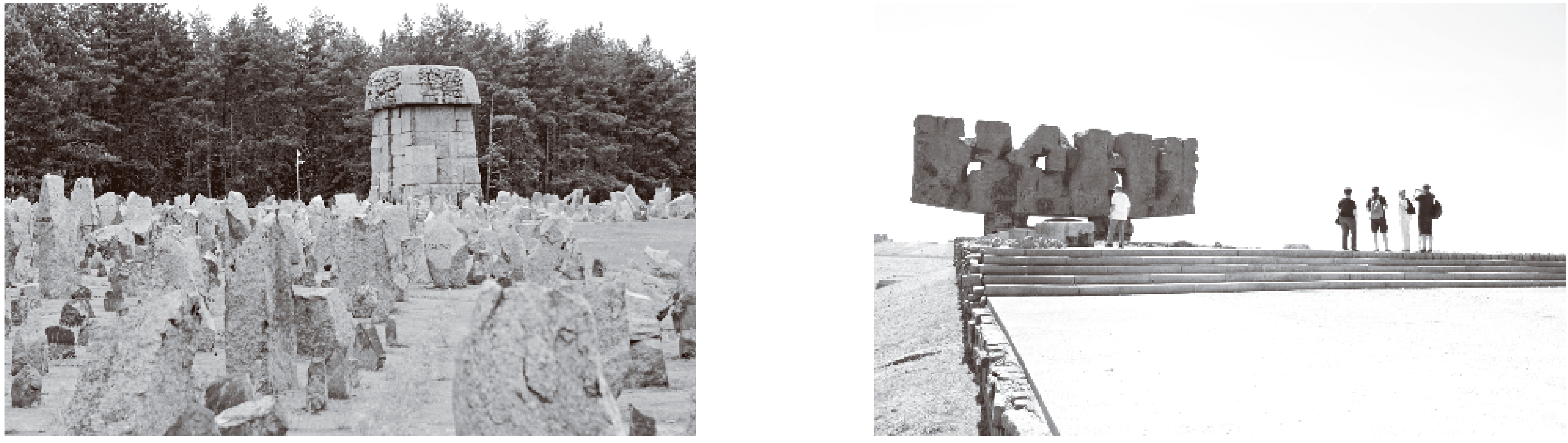
camp de

d'extermination à Lublin,

Majdanek.

$\Leftrightarrow$ Vue ensemble du camp

Mausolée, réalisé par
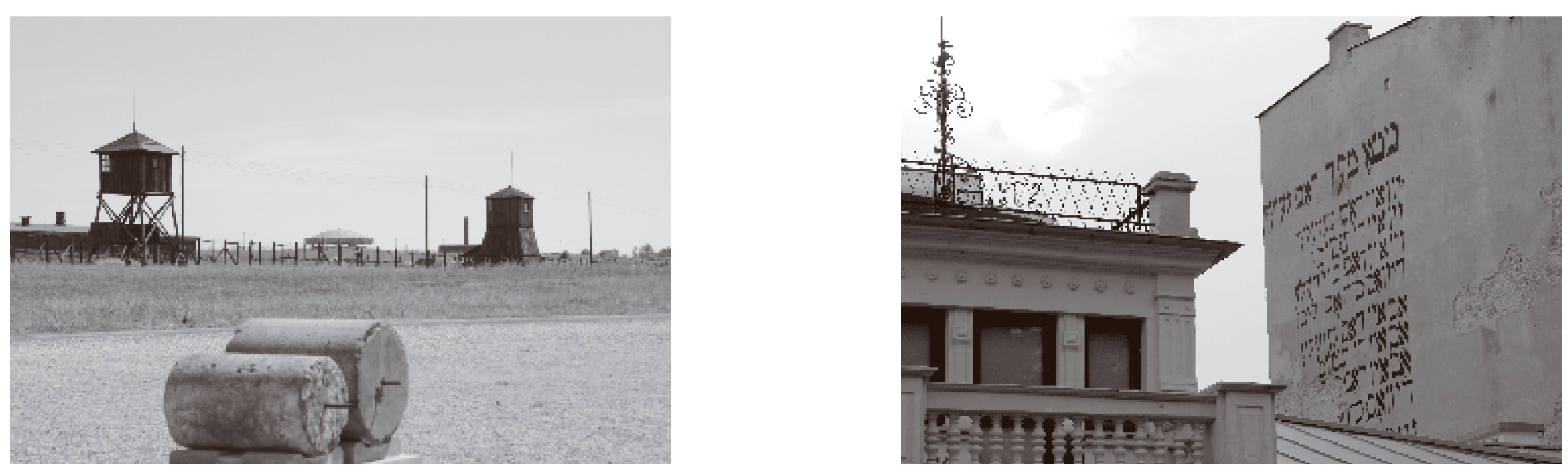

$\diamond$ Lublin.

$\checkmark$ Ce quil reste de

hlagplatz de Lublin.
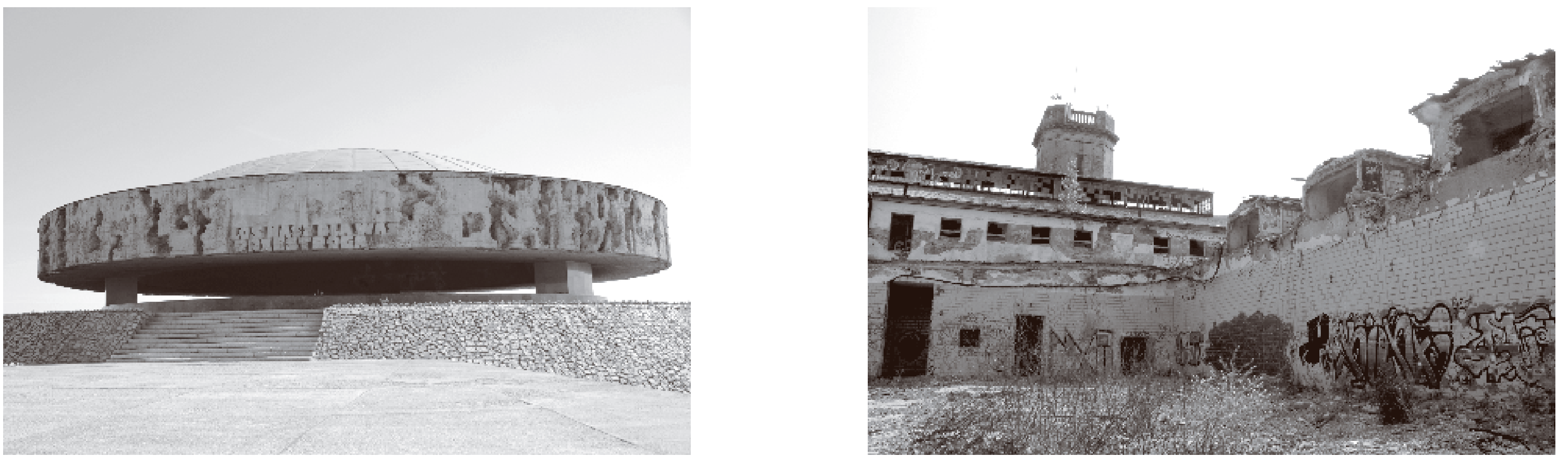

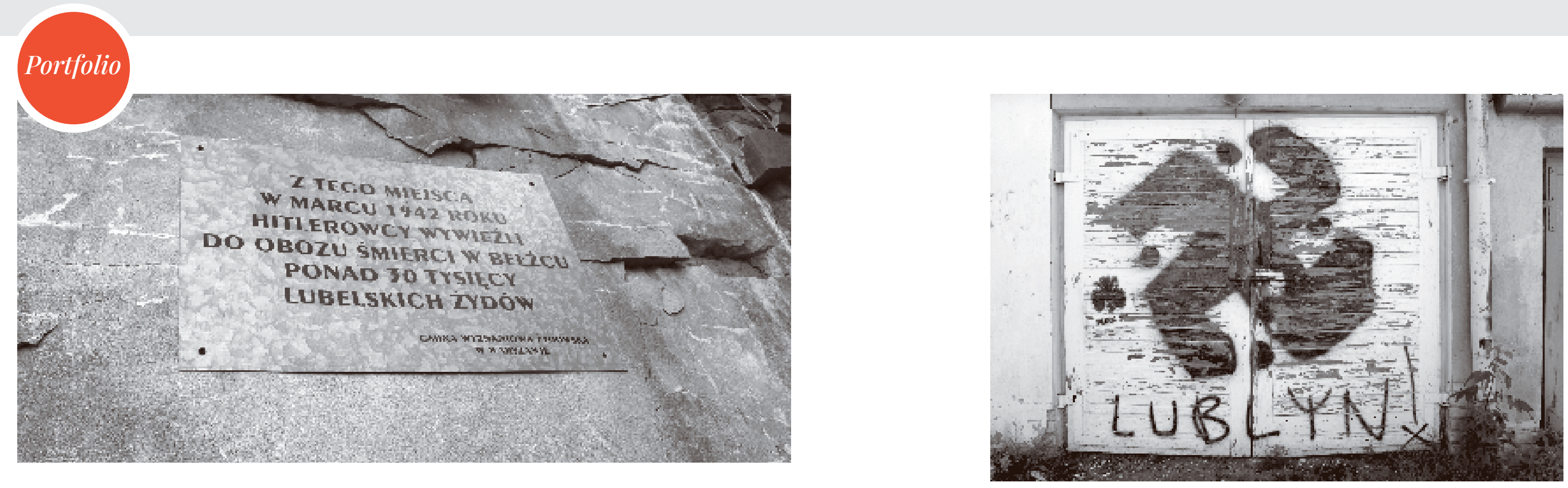

$\diamond$ Graffiti antisémite à Lublin (ancien quartier

Rénéral de l'Aktion

de 1941 à 1943).

La plaque commémorative de

en polonais : « de ce lieu, en mars 1942

les nazis ont déporté au camp de la mort

de Betżec plus de 30000 Juifs

de Lublin ").

$\diamond$ Mur avec la plaque commémorative

accompagnée graffiti.

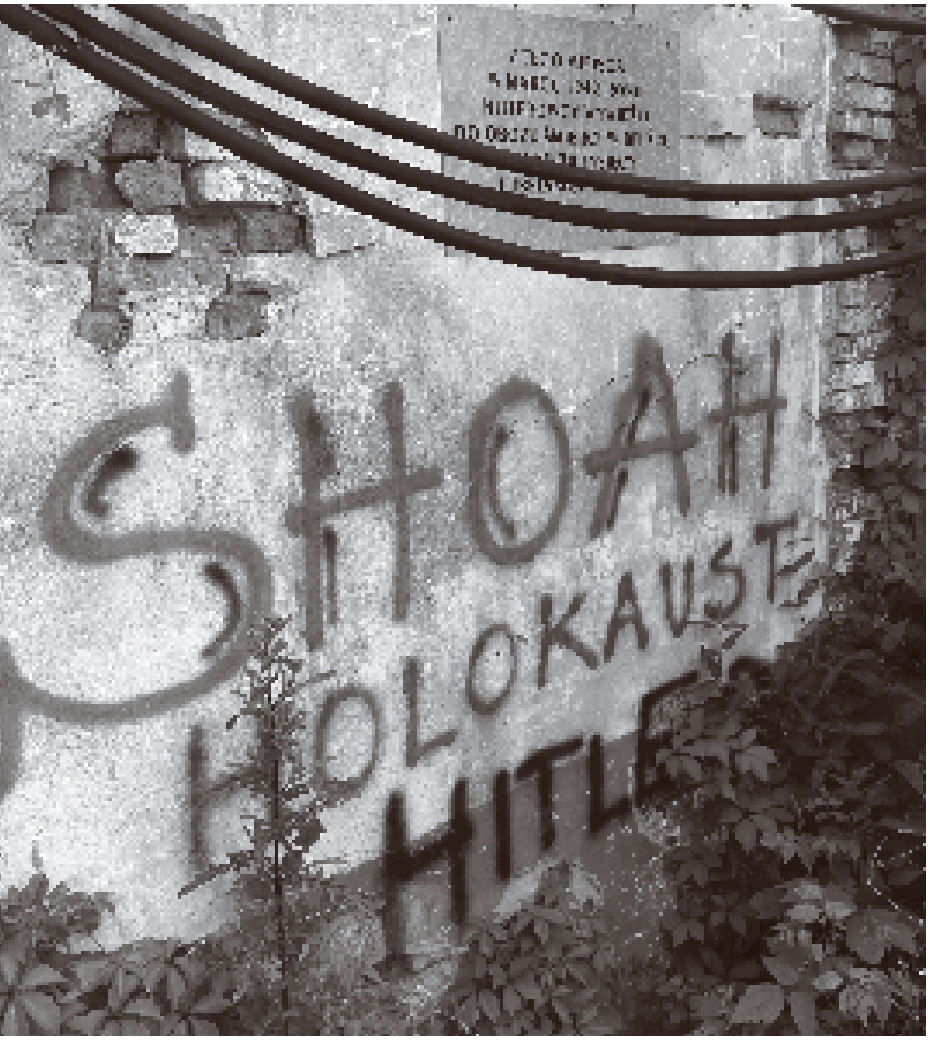

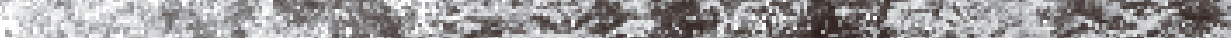

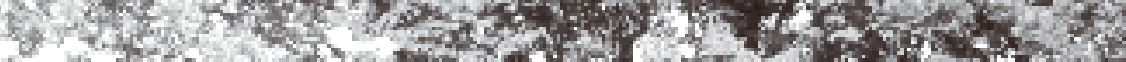

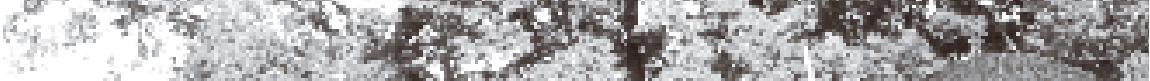

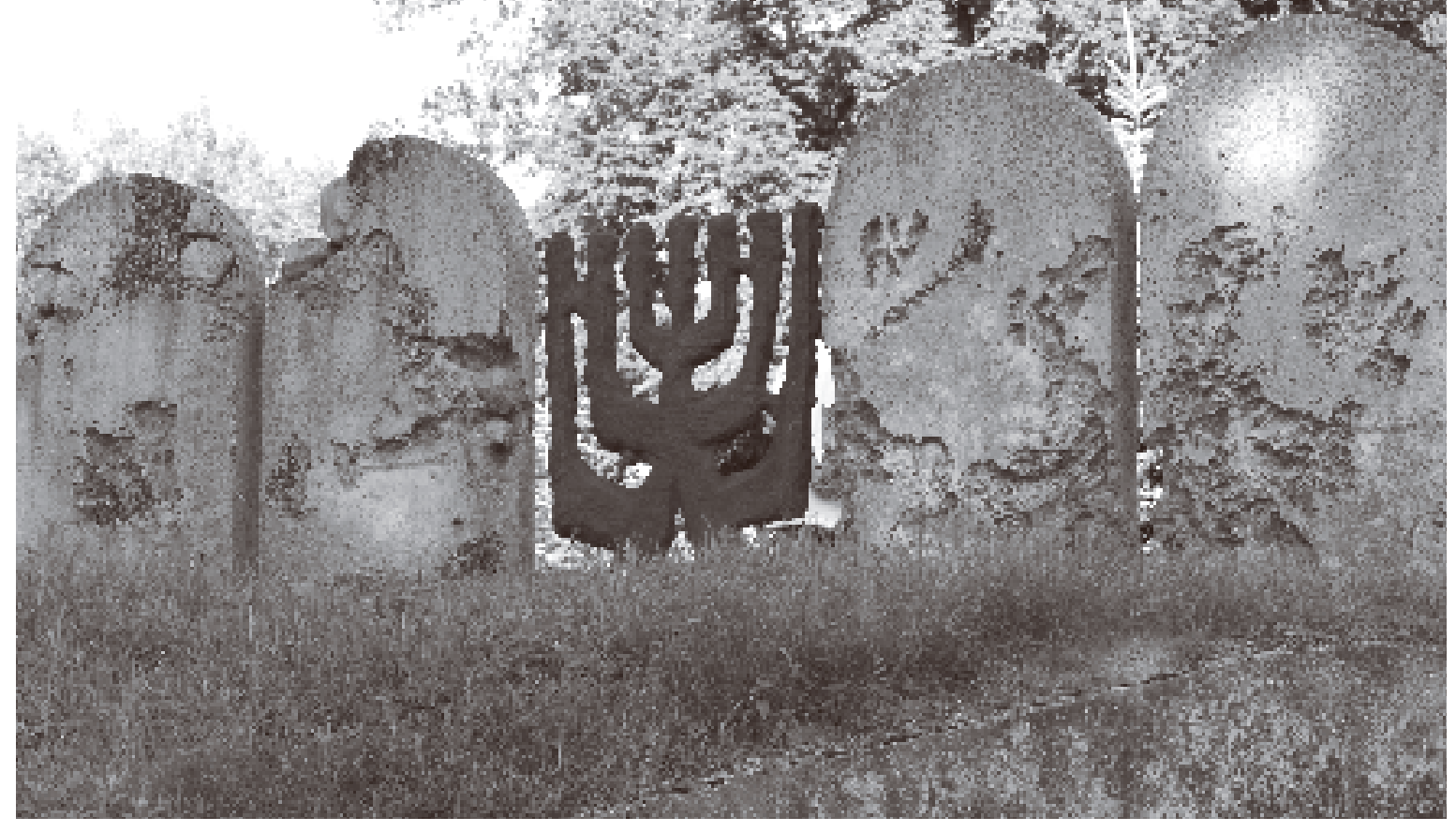



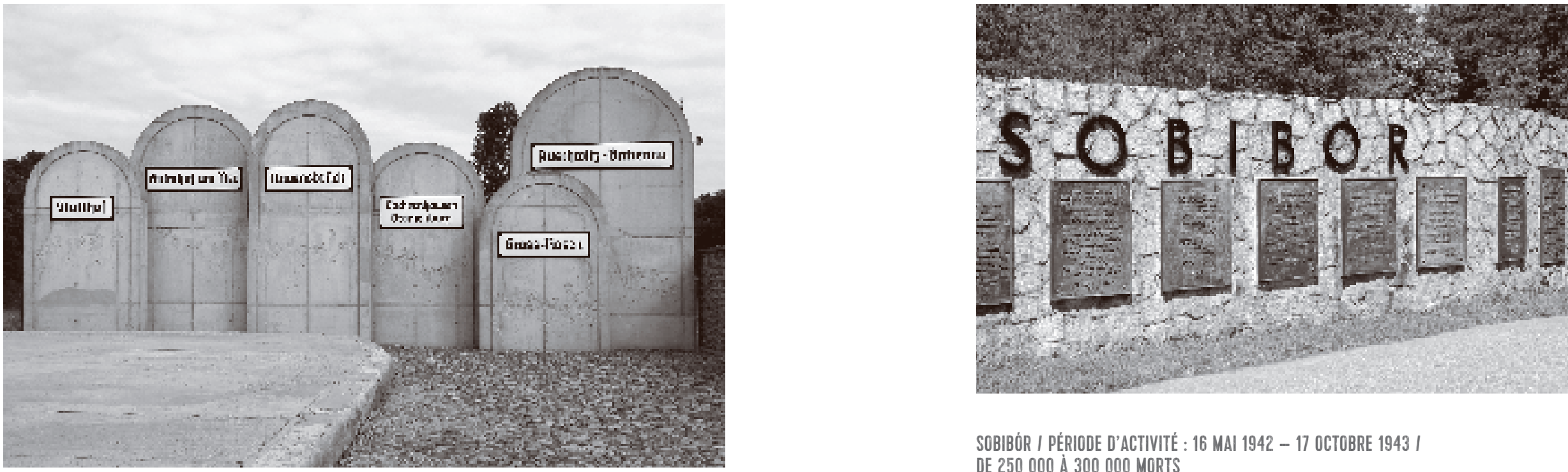

$\diamond$ Radegast, lieu e déportation (Łódź)

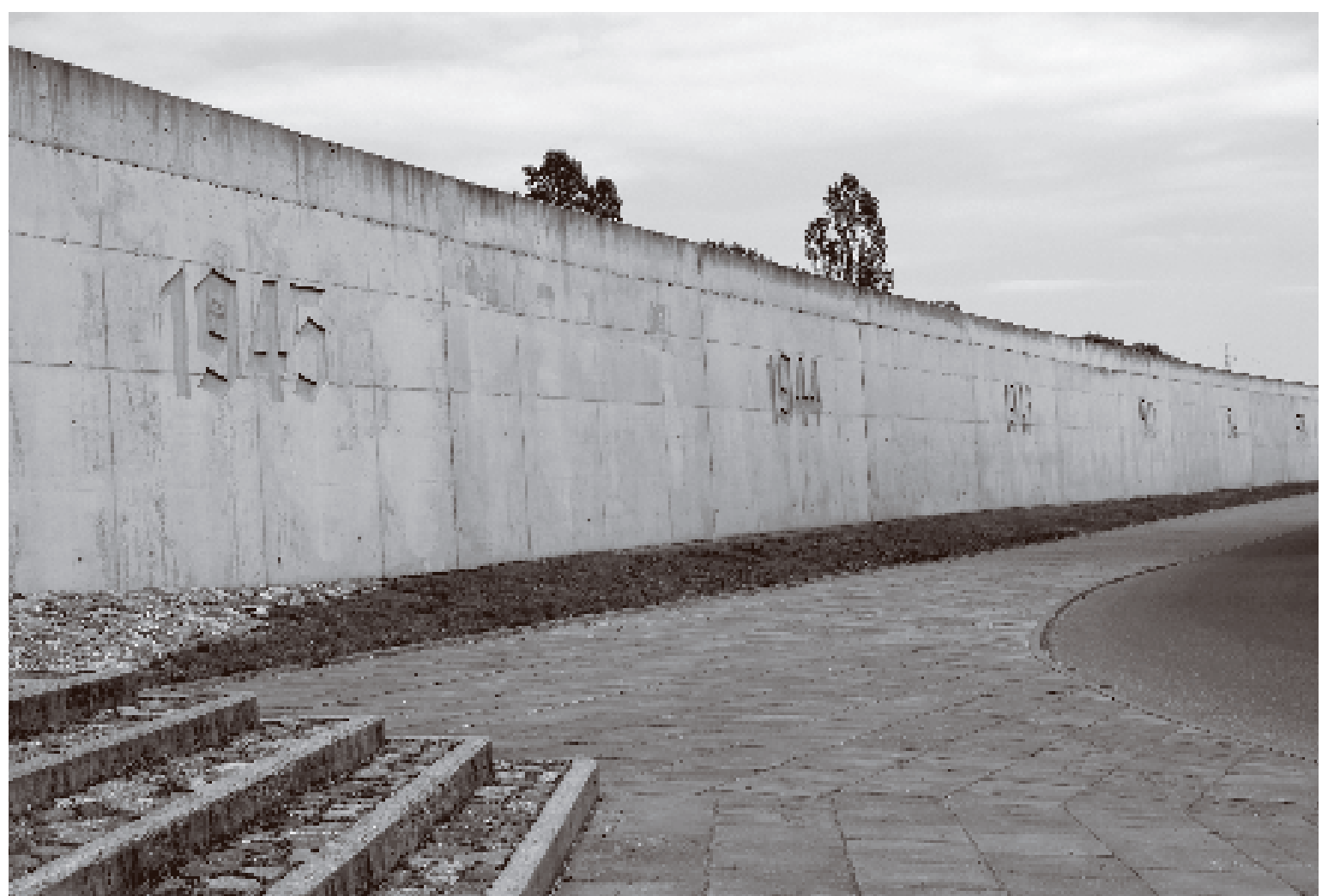

SOBIBÓR I PÉRIOOE D'ACTIVITÉ : 16 MAl 1942 - 17 OCTOBRE 1943 I DE 250000 Aे 300000 MORTS $\checkmark$ Lancien centre

d'extermination à Sobibór
Monuments commémoratifs de l'ancien centre dextermination à Sobibor

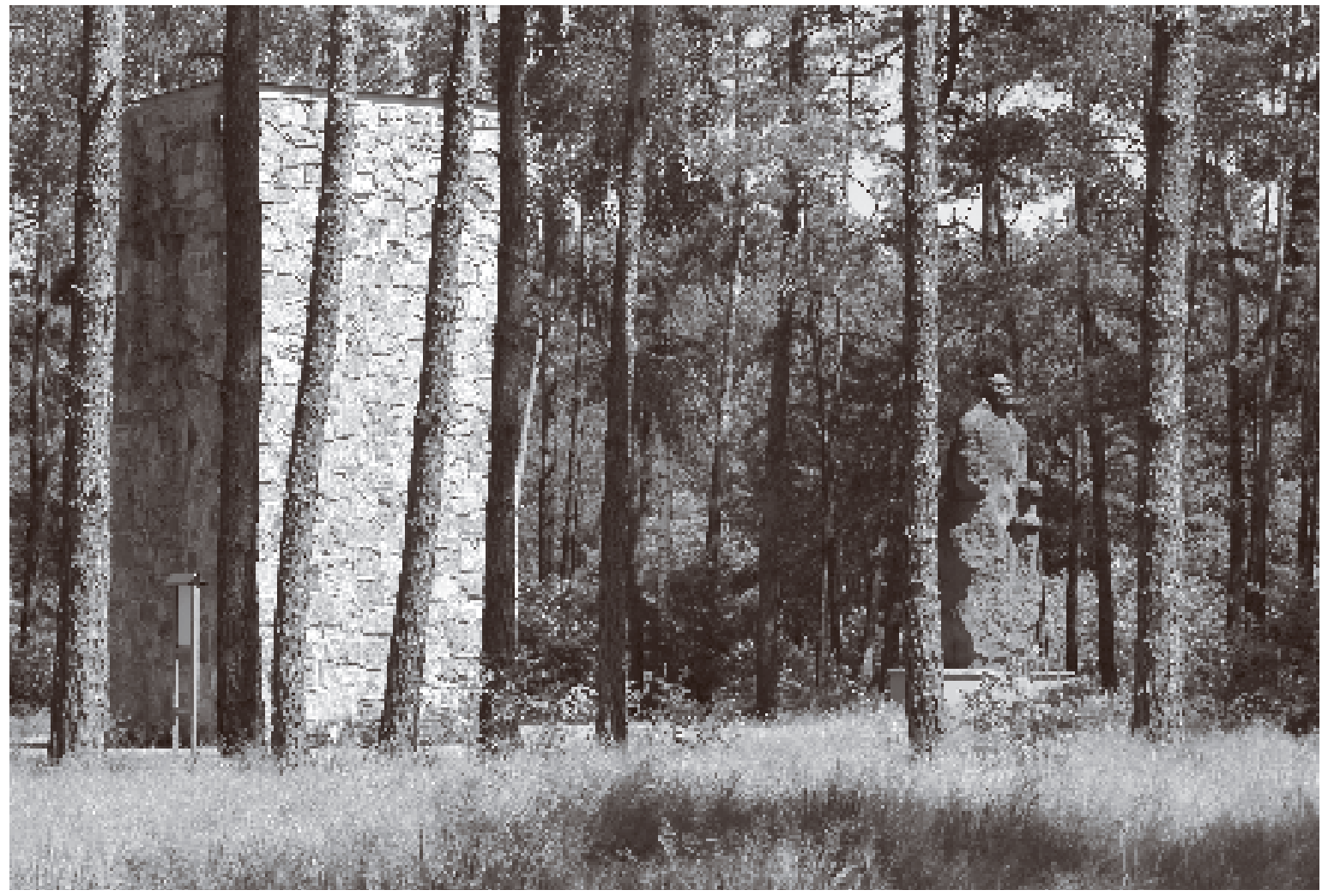




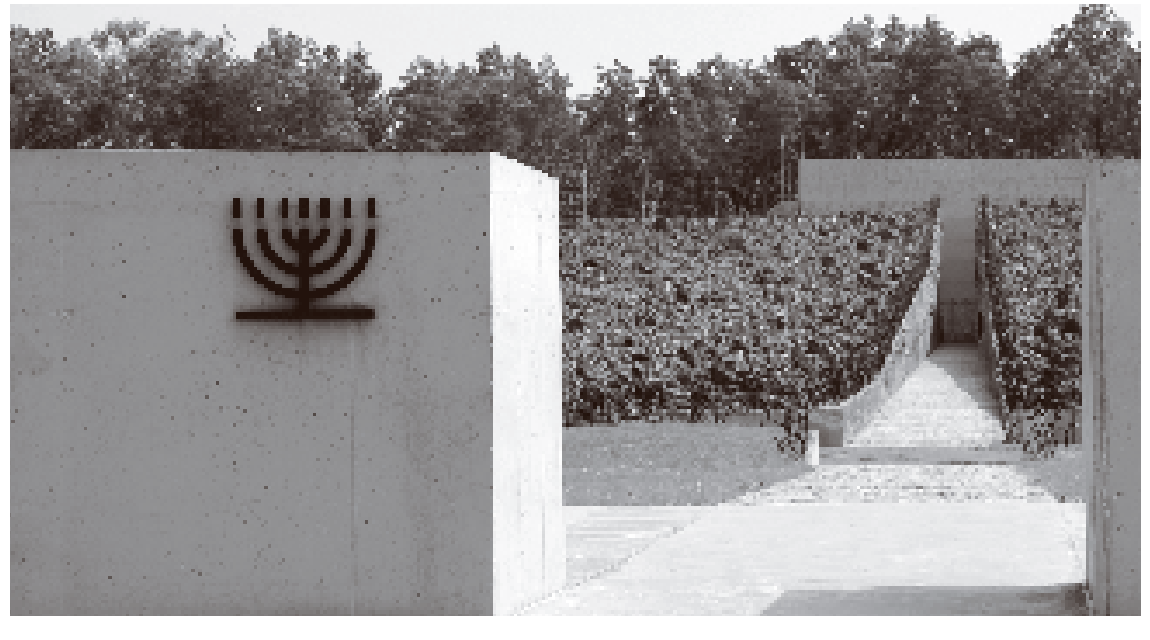

BEEżeC I PÉRIODE d’ACTIVITÉ : 17 MARS 1942 - 12 DÉCEMBRE 1942 I ENTRE 434000 ET 600000 MORTS

Vue d'ensemble du lieu de mémoire $\mathrm{de}$ lancien centre d'extermination à Bełżec

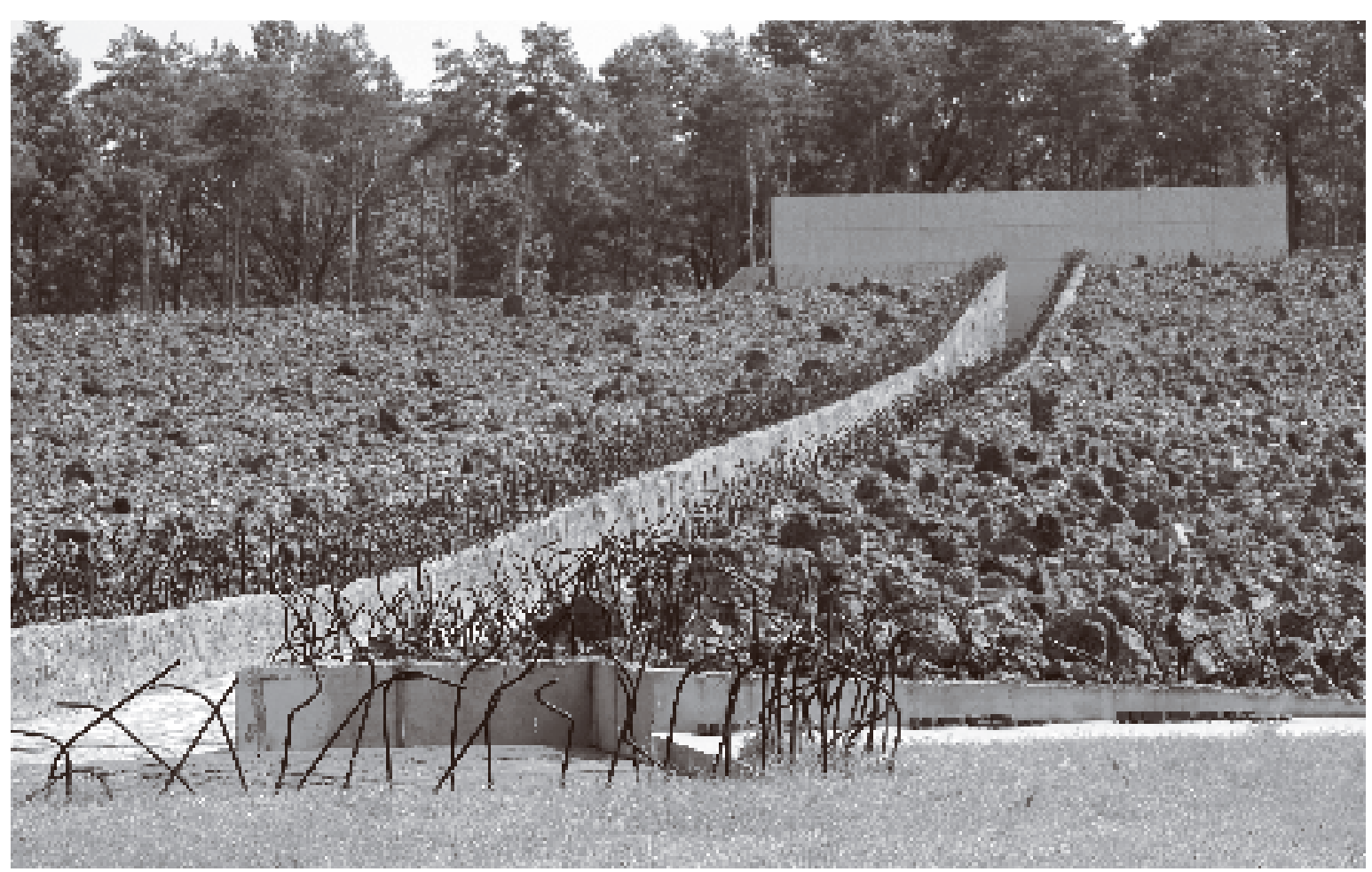

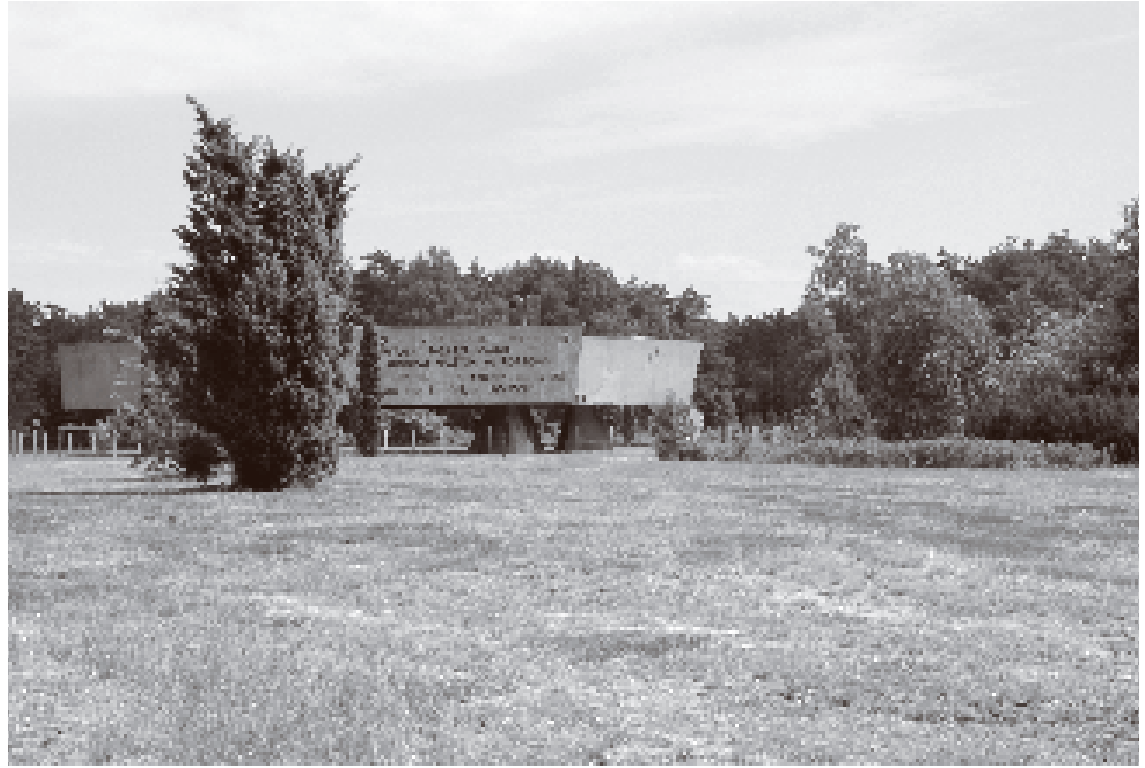

$\diamond$ Clairière de la forêt de Rzuchów, non loin du centre de mise à mort de Chelmno nad Nerem, ou les Juifs gazés dans les

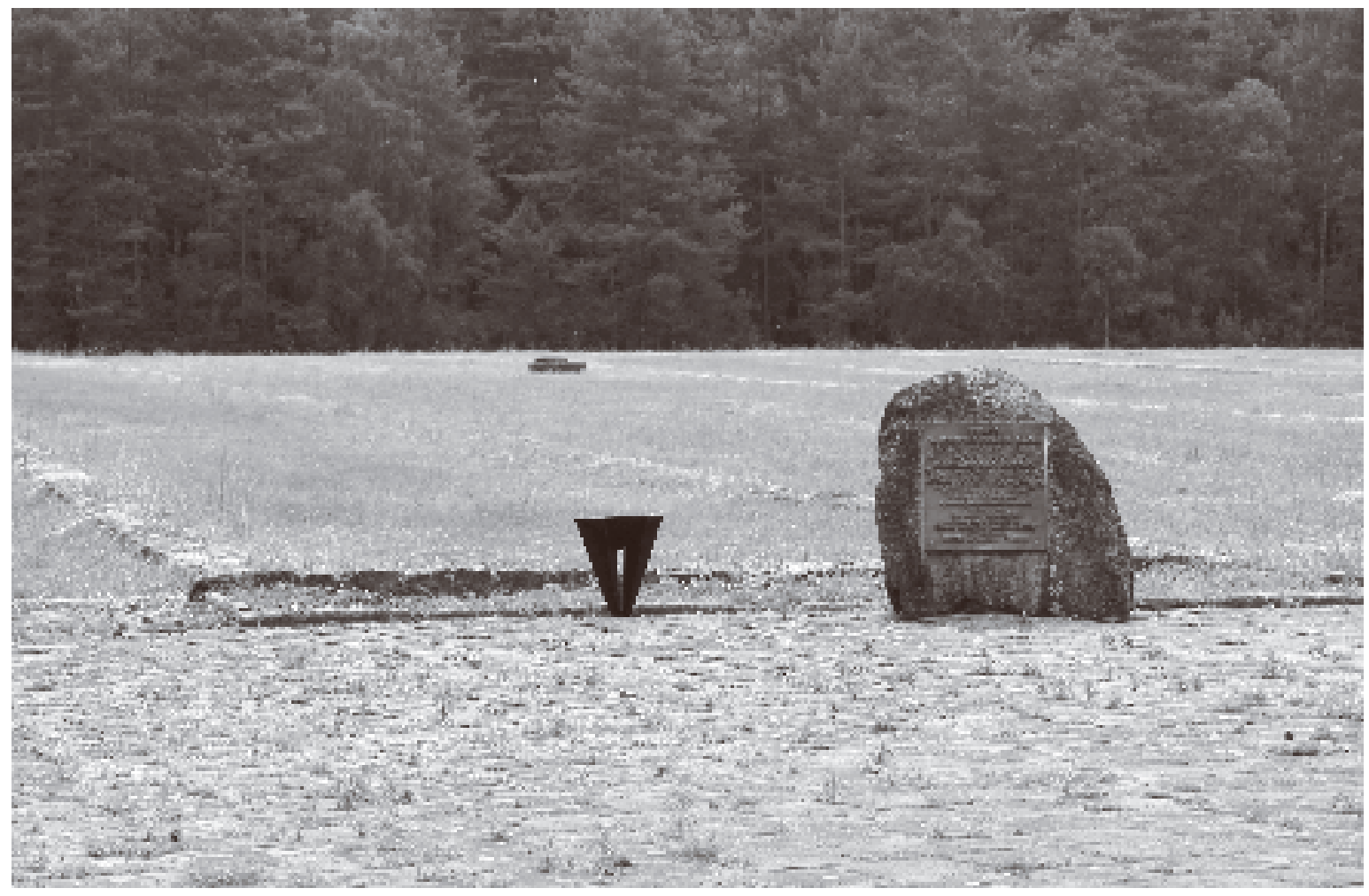

